\title{
Antibiotic susceptibility profiles of Mycoplasma synoviae strains originating from Central and Eastern Europe
}

\author{
Zsuzsa Kreizinger ${ }^{1}$, Dénes Grózner ${ }^{1}$, Kinga M. Sulyok ${ }^{1}$ Kristin Nilsson', Veronika Hrivnák , Dušan Benčina² \\ and Miklós Gyuranecz ${ }^{1 *}$
}

\begin{abstract}
Background: Mycoplasma synoviae causes infectious synovitis and respiratory diseases in chickens and turkeys and may lead to egg shell apex abnormalities in chickens; hence possesses high economic impact on the poultry industry. Control of the disease consists of eradication, vaccination or medication. The aim of the present study was to determine the in vitro susceptibility to 14 different antibiotics and an antibiotic combination of M. synoviae strains originating from Hungary and other countries of Central and Eastern Europe.

Results: Minimal inhibitory concentration (MIC) values of a total of $41 \mathrm{M}$. synoviae strains were determined by the microbroth dilution method. The strains were collected between 2002 and 2016 and originated from Hungary $(n=26)$, Austria $(n=3)$, the Czech Republic $(n=3)$, Slovenia $(n=3)$, Ukraine $(n=3)$, Russia $(n=2)$ and Serbia $(n=1)$. Tetracyclines (with $\mathrm{MIC}_{50}$ values of $0.078 \mu \mathrm{g} / \mathrm{ml}, \leq 0.25 \mu \mathrm{g} / \mathrm{ml}$ and $0.5 \mu \mathrm{g} / \mathrm{ml}$ for doxycycline, oxytetracycline and chlortetracycline, respectively), macrolides (with $\mathrm{MIC}_{50}$ values of $\leq 0.25 \mu \mathrm{g} / \mathrm{ml}$ for tylvalosin, tylosin and tilmicosin), pleuromutilins (with $\mathrm{MIC}_{50}$ values of $0.078 \mu \mathrm{g} / \mathrm{ml}$ and $\leq 0.039 \mu \mathrm{g} / \mathrm{ml}$ for tiamulin and valnemulin) and the combination of lincomycin and spectinomycin $\left(\mathrm{MIC}_{50} 1 \mu \mathrm{g} / \mathrm{ml}(0.333 / 0.667 \mu \mathrm{g} / \mathrm{ml})\right)$ were found to be the most effective antibiotic agents against M. synoviae in vitro. High MIC values were detected in numerous strains for fluoroquinolones (with $\mathrm{MIC}_{50}$ values of $1.25 \mu \mathrm{g} / \mathrm{ml}$ and $2.5 \mu \mathrm{g} / \mathrm{ml}$ for enrofloxacin and difloxacin), neomycin (MIC $5032 \mu \mathrm{g} / \mathrm{ml}$ ), spectinomycin (MIC $502 \mu \mathrm{g} / \mathrm{ml}$ ), lincomycin ( $\mathrm{MIC}_{50} 0.5 \mu \mathrm{g} / \mathrm{ml}$ ) and florfenicol $\left(\mathrm{MIC}_{50} 4 \mu \mathrm{g} / \mathrm{ml}\right.$ ). Nevertheless, strains with elevated MIC values were detected for most of the applied antibiotics.
\end{abstract}

Conclusions: In the medical control of M. synoviae infections the preliminary in vitro antibiotic susceptibility testing and the careful evaluation of the data are crucial. Based on the in vitro examinations doxycycline, oxytetracycline, tylvalosin, tylosin and pleuromutilins could be recommended for the therapy of M. synoviae infections in the region.

Keywords: Antibiotic resistance, Chicken, Turkey, MIC, Microbroth dilution, Mycoplasma synoviae

\section{Background}

Mycoplasma synoviae is a cell wall-less pathogen which has significant economical impact in the poultry industry [1]. Clinical signs caused by this bacterium comprise synovitis and respiratory diseases in chickens and turkeys, and mainly in commercial egg layers the reduction of egg production and hatchability, and egg shell apex abnormalities [2]. The severity of the clinical signs may

\footnotetext{
* Correspondence: m.gyuranecz@gmail.com

${ }^{1}$ Institute for Veterinary Medical Research, Centre for Agricultural Research,

Hungarian Academy of Sciences, Hungária körút 21, Budapest 1143, Hungary

Full list of author information is available at the end of the article
}

vary from sub-clinical to severe forms and is aggravated by the presence of other pathogens (e.g. infectious bronchitis virus, Newcastle disease virus, influenza A virus, Escherichia coli or other mycoplasmas) and inadequate housing conditions [3, 4].

The three main approaches for the control of the disease are eradication followed by prevention, vaccination or medication. While eradication and vaccination provide long-term solution for the control of mycoplasmosis, medication can be a prompt and effective tool to reduce the economic losses by mitigating egg transmission and clinical signs [1]. However, antibiotic susceptibility 
profile should first be determined to maximize treatment efficacy [5].

Due to their cell wall-less characteristic mycoplasmas are readily resistant to $ß$-lactam antibiotics and as they do not synthesize folic acid sulphonamides, sulfones or trimethoprim are ineffective against these pathogens also [6]. Natural resistance to erythromycin and other 14membered ring macrolides was described in M. synoviae [7]. Mycoplasmas showed susceptibility to tetracyclines, fluoroquinolones and macrolides both in vitro and in vivo, and the efficacy of tiamulin and the combination of lincomycin and spectinomycin against $M$. synoviae under experimental conditions had been proved long before [5, 7-14]. In vitro determination of antibiotic susceptibility of M. synoviae is an essential tool for the choice of the appropriate antibiotic agent in the therapy with taking in consideration the factors which may influence the antimicrobial effect in vivo (e.g. biofilm synthesis) [15]. However, the performance of the in vitro tests in the case of mycoplasmas is time-consuming and requires special techniques, thus usually it is not carried out in routine diagnostics and comparable data about the antibiotic susceptibility of $M$. synoviae strains originating from Europe are scarce in the literature also $[5,7,13,16,17]$.

In the present study the antibiotic susceptibility profile of $M$. synoviae strains originating from Central and Eastern Europe was determined by microbroth dilution method in the case of antibiotics commonly used in veterinary practice and which have potential to be used against avian mycoplasmosis.

\section{Methods}

M. synoviae strains were isolated from trachea swabs collected from turkeys and chickens originating from the Central and Eastern European region between 2014 and 2016. Production phase of the sampled chickens varied among breeders, commercial layers and broilers, while only meat-type turkeys were examined in the study (Table 1). Ethical approval and specific permission were not required for the study as all samples were collected by the authors during routine diagnostic examinations or necropsies with the consent of the owners. Trachea swabs were washed in $2 \mathrm{ml}$ modified Frey's broth medium [18] and incubated at $37{ }^{\circ} \mathrm{C}$ with $5 \% \mathrm{CO}_{2}$ atmosphere. The broth medium consisted of $0.225 \mathrm{~g} / \mathrm{ml}$ Frey Mycoplasma broth base, 20\% porcine serum, $0.01 \%$ NAD, $0.01 \%$ cysteine, $200 \mathrm{IU} / \mathrm{ml}$ penicillin $\mathrm{G}, 0.5 \%$ glucose, $0.5 \%$ pyruvate and $0.005 \%$ phenol red in distilled water; all products originated from Sigma-Aldrich, Germany. Strains were gained after one-time filter cloning, minimizing the in vitro mutations of the isolates. The QIAamp DNA Mini Kit (Qiagen Inc., Hilden, Germany) was used for DNA extraction according to the manufacturers' instructions for Gram-negative bacteria. The purity of the cultures was confirmed by a universal Mycoplasma PCR system targeting the 16S/23S rRNA intergenic spacer region in Mycoplasmatales [19] followed by sequencing on an ABI Prism 3100 automated DNA sequencer (Applied Biosystems, Foster City, CA), sequence analysis and BLAST search. Out of a total of $41 \mathrm{M}$. synoviae strains tested in the study 26 strains originated from Hungary, three strains each from Austria, the Czech Republic and from Ukraine, two strains from Russia and one from Serbia (Table 1). Also, three strains isolated in Slovenia between 2002 and 2008 were included in the study. The number of colour changing units $(\mathrm{CCU})$ was calculated by microbroth dilution method, from the highest dilution showing colour change (red to yellow shift) after two weeks of incubation [20].

The following antimicrobial agents were examined during the microbroth dilution tests: the fluoroquinolones: enrofloxacin and difloxacin; the aminocyclitol: spectinomycin; the aminoglycoside: neomycin; the lincosamide: lincomycin; the tetracyclines: doxycycline, oxytetracycline and chlortetracycline; the macrolides: tylosin and tilmicosin; the pleuromutilins: tiamulin and valnemulin; and the amphenicol: florfenicol; all products originated from VETRANAL, Sigma-Aldrich, Germany. Lincomycin and spectinomycin were applied in combination as well, in a ratio of 1:2. The macrolide tylvalosin (Aivlosin, ECO Animal Health Ltd., UK) was also included in the examinations. The antibiotics were diluted and stored according to the recommendations of Hannan [20]. Stock solutions of $1 \mathrm{mg} / \mathrm{ml}$ fluoroquinolones were prepared in $0.1 \mathrm{M} \mathrm{NaOH}$; stock solution of $1 \mathrm{mg} / \mathrm{ml}$ florfenicol was prepared in 96\% ethanol and in sterile distilled water; and the rest of the stock solutions of $1 \mathrm{mg} / \mathrm{ml}$ were prepared in sterile distilled water and stored at $-70{ }^{\circ} \mathrm{C}$. Freshly prepared two-fold dilutions were used in each microtest after checking the thawed antibiotic solutions for any visible changes in their consistency. The concentration range of the antibiotics was selected to cover values previously suggested to reflect susceptibility, intermediate susceptibility or resistance to the tested agents or which were used in previous publications (Table 2), in details: $0.039-10 \mu \mathrm{g} / \mathrm{ml}$ for fluoroquinolones, doxycycline and pleuromutilins, 0.25 $64 \mu \mathrm{g} / \mathrm{ml}$ for neomycin, spectinomycin, lincomycin, oxytetracycline, chlortetracycline and macrolides, $0.125-$ $32 \mu \mathrm{g} / \mathrm{ml}$ for florfenicol and $0.25-64 \mu \mathrm{g} / \mathrm{ml}(0.083 /$ $0.167-21.333 / 42.666 \mu \mathrm{g} / \mathrm{ml}$ ) for the combination of lincomycin and spectinomycin.

Microbroth dilution examinations were performed according to Hannan [20] on $10^{4}-10^{5} \mathrm{CCU} / \mathrm{ml}$ of the strains. In brief, the tests were performed in 96-well microtiter plates containing modified Frey's broth 


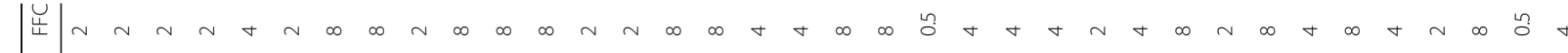
费 vi vi vi vi vi vi vi vi vi vi vi vi vi vi vi vi vi vi vi vi vi vi vi vi vi vi vi vi vi vi vi vi vi vi vi vi

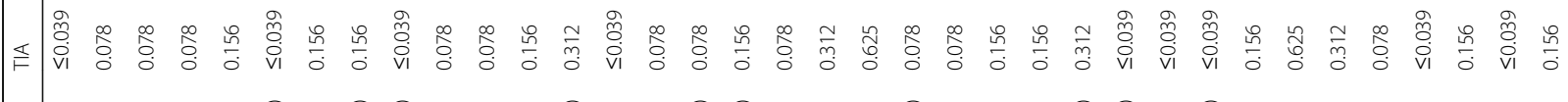

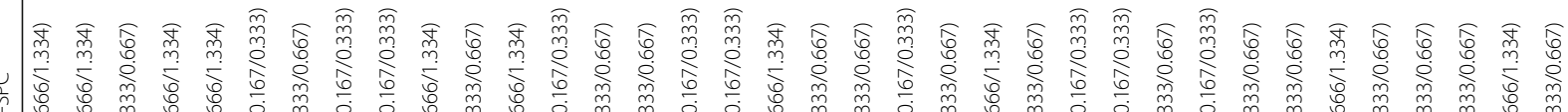

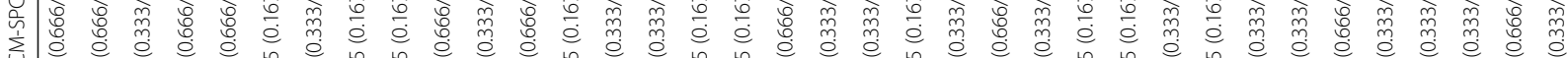

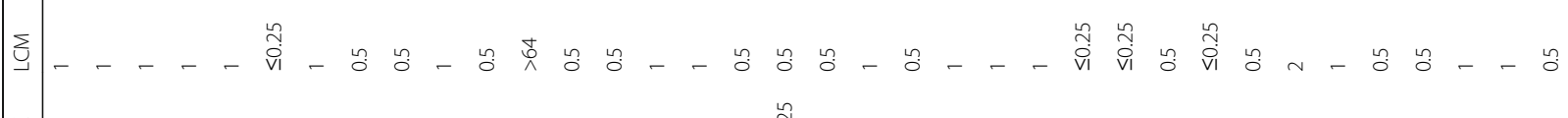

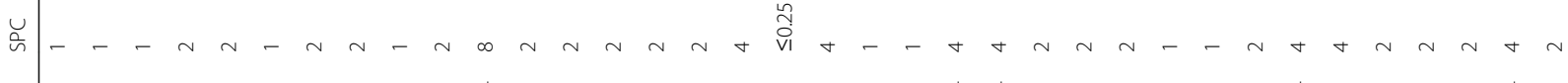

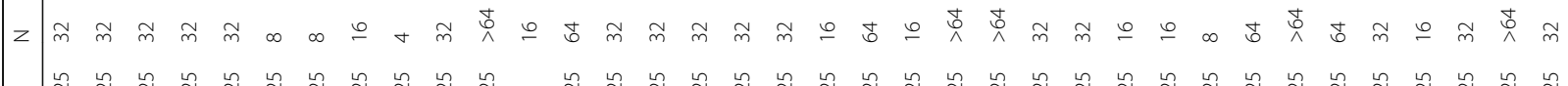

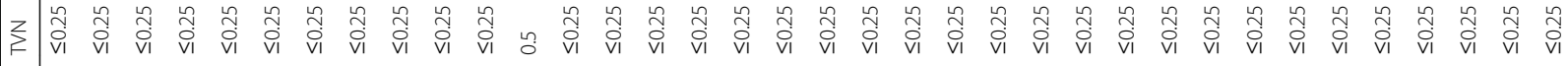

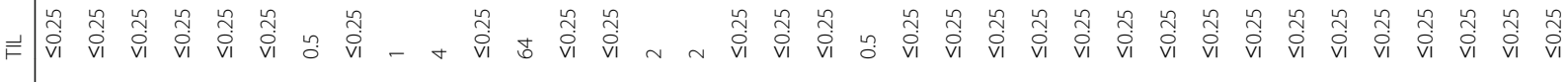

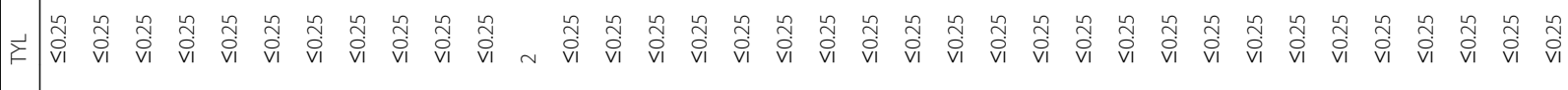

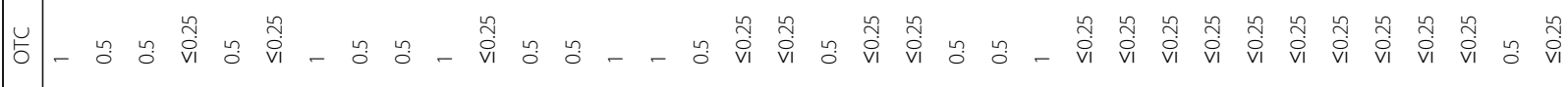

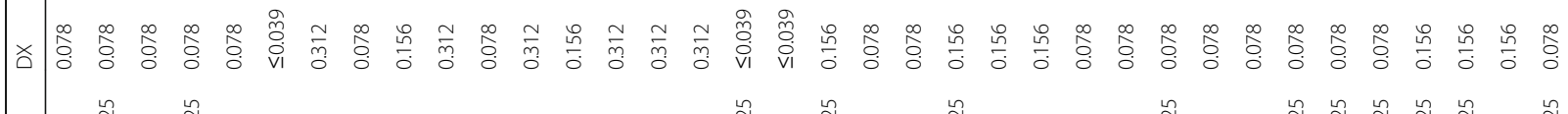

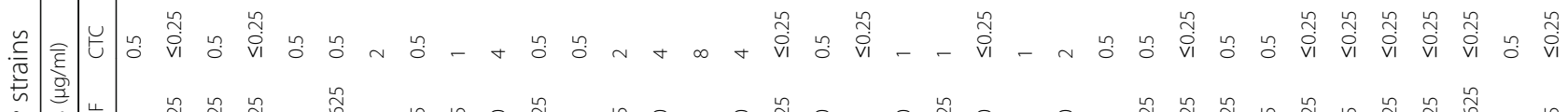

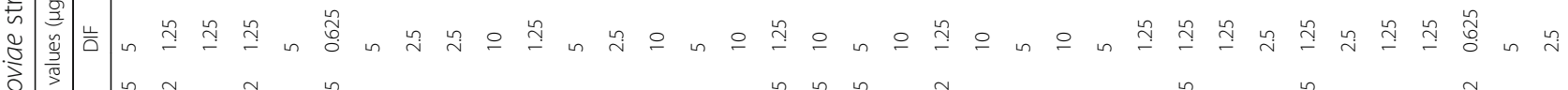

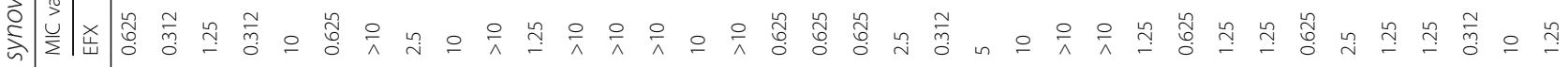
旁

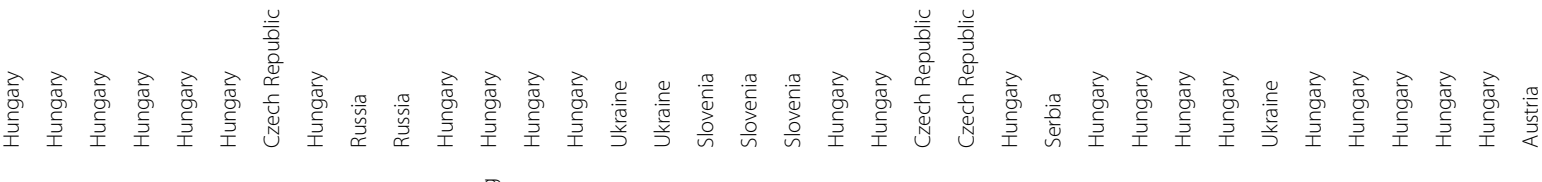

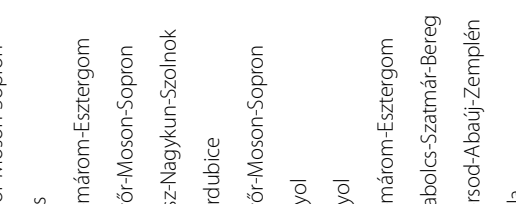




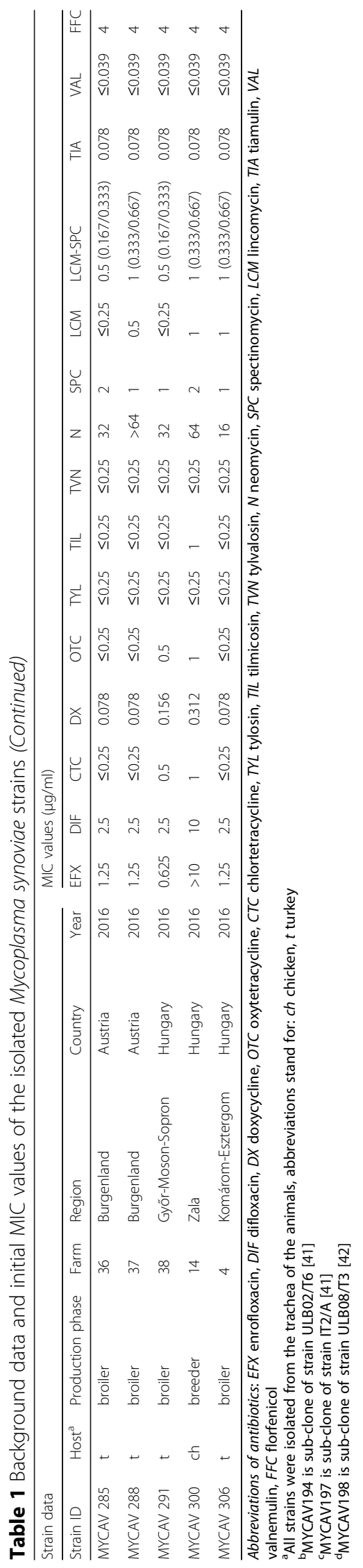


Table 2 Summary of MIC range, $\mathrm{MIC}_{50}$ and $\mathrm{MIC}_{90}$ values $(\mu \mathrm{g} / \mathrm{ml})$ of the isolated Mycoplasma synoviae strains with the suggested non-official breakpoints (in $\mu \mathrm{g} / \mathrm{ml}$; S: susceptible, R: resistant) and MIC values for the type strain WVU1853

\begin{tabular}{|c|c|c|c|c|c|c|c|c|c|}
\hline & $\begin{array}{l}\text { Non-official } \\
\text { breakpoints }\end{array}$ & $\begin{array}{l}\text { WVU1853 } \\
\text { initial }\end{array}$ & $\begin{array}{l}\text { WVU1853 } \\
\text { final }\end{array}$ & Range initial & Range final & $\begin{array}{l}\mathrm{MIC}_{50} \\
\text { initial }\end{array}$ & $\begin{array}{l}\mathrm{MlC}_{50} \\
\text { final }\end{array}$ & $\begin{array}{l}\mathrm{MIC}_{90} \\
\text { initial }\end{array}$ & $\begin{array}{l}\mathrm{MIC}_{90} \\
\text { final }\end{array}$ \\
\hline \multicolumn{10}{|l|}{ Fluoroquinolones } \\
\hline Enrofloxacin & $\mathrm{S} \leq 0.5 ; R \geq 2[5]$ & 0.312 & 1.25 & $0.312->10$ & $0.312->10$ & 1.25 & 1.25 & $>10$ & $>10$ \\
\hline Difloxacin & $\mathrm{S} \leq 0.5 ; R \geq 4[5]$ & $1.25-2.5$ & $1.25-2.5$ & $0.625->10$ & $0.625->10$ & 2.5 & 2.5 & 10 & $>10$ \\
\hline \multicolumn{10}{|l|}{ Aminocyclitol } \\
\hline Spectinomycin & $\mathrm{S} \leq 2 ; R>4[28]$ & 2 & 8 & $\leq 0.25-8$ & $1-16$ & 2 & 2 & 4 & 8 \\
\hline \multicolumn{10}{|l|}{ Aminoglycoside } \\
\hline Neomycin & $S \leq 4 ; R>4[25]$ & $64->64$ & $>64$ & $4->64$ & $8->64$ & 32 & $>64$ & $>64$ & $>64$ \\
\hline \multicolumn{10}{|l|}{ Lincosamide } \\
\hline Lincomycin & $\mathrm{S} \leq 2 ; R \geq 8$ & 0.5 & 0.5 & $\leq 0.25->64$ & $\leq 0.25->64$ & 0.5 & 1 & 1 & 4 \\
\hline \multicolumn{10}{|l|}{ Tetracyclines } \\
\hline Doxycycline & $\mathrm{S} \leq 4 ; R \geq 16[25]$ & $\leq 0.039$ & 0.156 & $\leq 0.039-0.312$ & $0.078-1.25$ & 0.078 & 0.156 & 0.312 & 0.625 \\
\hline Oxytetracycline & $S \leq 4 ; R \geq 16[5]$ & $\leq 0.25$ & 0.5 & $\leq 0.25-1$ & $\leq 0.25-8$ & $\leq 0.25$ & 1 & 1 & 4 \\
\hline Chlortetracycline & $S \leq 4 ; R \geq 16[25]$ & 0.5 & 1 & $\leq 0.25-8$ & $\leq 0.25-16$ & 0.5 & 2 & 2 & 8 \\
\hline \multicolumn{10}{|l|}{ Macrolides } \\
\hline Tylosin & $S \leq 1 ; R \geq 4[5]$ & $\leq 0.25$ & $\leq 0.25$ & $\leq 0.25-2$ & $\leq 0.25-8$ & $\leq 0.25$ & $\leq 0.25$ & $\leq 0.25$ & $\leq 0.25$ \\
\hline Tilmicosin & $\mathrm{S} \leq 8 ; R \geq 32[5]$ & $\leq 0.25$ & $\leq 0.25$ & $\leq 0.25-64$ & $\leq 0.25->64$ & $\leq 0.25$ & $\leq 0.25$ & 1 & 2 \\
\hline Tylvalosin & $\mathrm{S} \leq 0.5 ; R>2[28]$ & $\leq 0.25$ & $\leq 0.25$ & $\leq 0.25-0.5$ & $\leq 0.25-1$ & $\leq 0.25$ & $\leq 0.25$ & $\leq 0.25$ & $\leq 0.25$ \\
\hline \multicolumn{10}{|l|}{ Pleuromutilins } \\
\hline Tiamulin & $S \leq 8 ; R \geq 16[7]$ & 0.078 & 0.078 & $\leq 0.039-0.625$ & $0.078-1.25$ & 0.078 & 0.156 & 0.312 & 0.312 \\
\hline Valnemulin & $\begin{array}{l}S \leq 0.125 \\
R>0.125[25]\end{array}$ & $\leq 0.039$ & $\leq 0.039$ & $\leq 0.039$ & $\leq 0.039$ & $\leq 0.039$ & $\leq 0.039$ & $\leq 0.039$ & $\leq 0.039$ \\
\hline \multicolumn{10}{|l|}{ Amphenicol } \\
\hline Florfenicol & $S \leq 2 ; R \geq 8[25]$ & $1-2$ & $1-4$ & $0.5-8$ & $1-16$ & 4 & 8 & 8 & 8 \\
\hline \multicolumn{10}{|l|}{ Combination } \\
\hline $\begin{array}{l}\text { Lincomycin: } \\
\text { Spectinomycin }\end{array}$ & $\begin{array}{l}S \leq 2(0.666 / 1.334) \\
R>4(1.332 / 2.668)[25]\end{array}$ & $\begin{array}{l}1 \\
(0.333 / 0.667)\end{array}$ & $\begin{array}{l}1-2 \\
(0.333 / 0.667- \\
0.666 / 1.334)\end{array}$ & $\begin{array}{l}0.5-2 \\
(0.167 / 0.333- \\
0.666 / 1.334)\end{array}$ & $\begin{array}{l}0.5-4 \\
(0.167 / 0.333- \\
1.332 / 2.668)\end{array}$ & $\begin{array}{l}1 \\
(0.333 / 0.667)\end{array}$ & $\begin{array}{l}1 \\
(0.333 / 0.667)\end{array}$ & $\begin{array}{l}2 \\
(0.666 / 1.334)\end{array}$ & $\begin{array}{l}2 \\
(0.666 / 1.334)\end{array}$ \\
\hline
\end{tabular}

medium, using growth controls (broth medium without antibiotic), sterility controls (broth medium without antibiotic and Mycoplasma inoculum), $\mathrm{pH}$ controls (broth medium adjusted to $\mathrm{pH}$ 6.8) and quality controls (the duplicate of the $M$. synoviae type strain WVU 1853, NCTC 10124). All strains were tested in duplicates.

The minimum inhibitory concentrations (MIC) were determined from the lowest concentration of the antibiotics where no $\mathrm{pH}$ and colour change of the broth was detected, meaning that the growth of the bacteria was completely inhibited in the broth. Initial MIC values were determined when the growth controls showed colour change. Final MIC values were determined when no further growth was detected, generally after two weeks of incubation. $\mathrm{MIC}_{50}$ and $\mathrm{MIC}_{90}$ values were defined as the lowest concentrations that inhibited the growth of $50 \%$ or $90 \%$ of the strains [20].

\section{Results}

The quality control type strain (WVU 1853, NCTC 10124) showed consistent results throughout the study and the data (Table 2) were in accordance with previously recorded MIC values gained by microbroth dilution method: ranges of initial MIC values were $0.125-0.5 \mu \mathrm{g} / \mathrm{ml}$ for enrofloxacin and difloxacin, $0.1-$ $0.125 \mu \mathrm{g} / \mathrm{ml}$ for oxytetracycline, $\leq 0.015 \mu \mathrm{g} / \mathrm{ml}$ for doxycycline, $0.025-0.06 \mu \mathrm{g} / \mathrm{ml}$ for tylosin, $0.015-$ $0.06 \mu \mathrm{g} / \mathrm{ml}$ for tilmicosin, and $\leq 0.03-0.1 \mu \mathrm{g} / \mathrm{ml}$ for tiamulin before $[5,7,13,17]$. Currently, there are no comparable MIC values available in the case of the M. synoviae type strain (WVU 1853, NCTC 10124) for the rest of the antibiotics tested in the present study. The ranges of the initial and final MIC values, $\mathrm{MIC}_{50}$ and $\mathrm{MIC}_{90}$ values for each antibiotic and for the combination are included in Table 2. In the cases of four antibiotics (oxytetracycline, chlortetracycline, neomycin and lincomycin) at least four-fold difference 
was observed in the $\mathrm{MIC}_{50}$ or $\mathrm{MIC}_{90}$ values when initial and final MIC values were compared (Tables 1 and 2 and Additional file 1). The initial MIC values are evaluated and discussed throughout the study [20]. The $\mathrm{MIC}_{50}$ values of the strains originating from different countries of the Central and Eastern European region showed high similarity, thus if otherwise not indicated the MIC values of all examined strains are evaluated together.

The distribution of the MIC values for enrofloxacin showed two main peaks (Fig. 1a1), while predominantly even distribution of the MIC values for difloxacin was observed (Fig. 1a2). Among the Hungarian strains the $\mathrm{MIC}_{50}$ values for enrofloxacin of the isolates originating from chickens $(10 \mu \mathrm{g} / \mathrm{ml}, n=11)$ was notably higher than of the strains originating from turkeys $(1.25 \mu \mathrm{g} / \mathrm{ml}$, $n=15$ ), which corresponds to the observed two-peaked distribution (Fig. 1a2). In this comparison, four-fold difference was detected between the $\mathrm{MIC}_{50}$ values for difloxacin (with $\mathrm{MIC}_{50} 1.25 \mu \mathrm{g} / \mathrm{ml}$ and $5 \mu \mathrm{g} / \mathrm{ml}$ of strains from turkeys and chickens, respectively) and the distribution of the MIC values for this agent differed remarkably according to the isolates' host of origin (Fig. 1b2). No outlier strains with high MIC values were observed for the tetracyclines doxycycline, oxytetracycline and chlortetracycline (Fig. 1c, d and e). The strains generally showed low MIC values for the three examined macrolides (Fig. 1f, g and h), with the exception of one strain (MYCAV 185), especially in the case of tilmicosin (MIC $64 \mu \mathrm{g} / \mathrm{ml}$ ). Strain MYCAV 185 was isolated from a backyard flock, where excess antibiotic usage was documented, and it showed elevated MIC values for most antibiotics tested. High MIC values were detected for neomycin in most strains (Fig. 1i), especially after two weeks of incubation (final $\mathrm{MIC}_{50}>64 \mu \mathrm{g} / \mathrm{ml}$, Table 2 and Additional file 1). The majority of the strains' MIC values for spectinomycin and for lincomycin distributed around the $\mathrm{MIC}_{50}$ values (Fig. $1 \mathrm{j}$ and $\mathrm{k}$ ). Outlier strains were detected for both antibiotics; one strain with low MIC value in the case of spectinomycin (MYCAV 197), and one with high MIC value in the case of lincomycin (MYCAV 185). When lincomycin and spectinomycin were applied in combination, the range of the MIC values slightly tightened, no outlier strains were detected and lower concentration of the individual antibiotics was sufficient in the combination to inhibit the growth of $50 \%$ of the strains (Fig. $1 \mathrm{j}, \mathrm{k}$ and $\mathrm{l}$ ). Pleuromutilins showed high efficacy against the $M$. synoviae strains (Fig. $1 \mathrm{~m}$ and $\mathrm{n}$ ). No growth was observed in the presence of valnemulin and most strains were inhibited at the $\mathrm{MIC}_{50}$ concentration of tiamulin. The MIC values of the majority of the strains grouped around the $\mathrm{MIC}_{50}$ value $(4 \mu \mathrm{g} / \mathrm{ml})$ in the case of florfenicol also (Fig. 10).

\section{Discussion}

Conventional methods for the determination of antibiotic susceptibility of mycoplasmas is time-consuming, laborious and requires special techniques, thus it is not performed routinely [20]. Moreover, the interpretation of the results is hampered by the lack of official standards. In the case of human pathogen mycoplasmas the Clinical and Laboratory Standards Institute (CLSI) has provided official breakpoints for certain antibiotics [21]. However, given the fastidious nature and inherent differences in the cultivation of these pathogens, procedures and media vary according to each of the examined species [22]. Initiations to establish standard CLSI protocols for mycoplasmas with veterinary relevance have been made, but for the time being the recommendations of Hannan [20] are supposed to be applied in these cases [23]. In the lack of official breakpoints, the data of the present study are interpreted according to values previously used in other publications $[5,7,13,20,24]$ or to breakpoints of other avian pathogens determined by the CLSI [25] (Table 2).

Susceptibility (MIC $\leq 0.5 \mu \mathrm{g} / \mathrm{ml}$ according to Landman et al. [5]) and also resistance (MICs $\geq 2$ or $4 \mu \mathrm{g} / \mathrm{ml}$ for enrofloxacin or difloxacin, respectively) [5] to fluoroquinolones have been described in $M$. synoviae strains before $[5,12,16,17,24]$. Differences in the antibiotic usage and density of poultry flocks were assumed to be responsible for the observed variations [17] and resistance to fluoroquinolones was described in Europe [5]. In the present study, elevated MIC values of fluoroquinolones were observed regardless of the strains' geographical origin. On the other hand, MIC values showed correlation with the host of origin, most probably in connection with the length of the hosts' production cycle. In the interpretation of Landman et al. [5], more than half of the Hungarian strains isolated from chickens (mainly breeders and layers) were regarded resistant to enrofloxacin ( $\mathrm{MIC} \geq 2 \mu \mathrm{g} / \mathrm{ml}$ ) and difloxacin (MIC $\geq 4 \mu \mathrm{g} / \mathrm{ml}$ ), while most of the strains from meat-type turkeys (short life production cycle) were considered susceptible or intermediately susceptible to these antibiotics.

The MIC values of tetracyclines also varied in previous works according to the strains' country of origin, with most European strains showing susceptibility $(\mathrm{MIC} \leq 4 \mu \mathrm{g} / \mathrm{ml})[20]$ to these agents $[5,12,13,16]$. In accordance with previous studies, all strains included in the current study showed high susceptibility to doxycycline and oxytetracycline, and chlortetracycline proved to be highly efficient at least against $90 \%$ of the strains.

The 16-membered ring macrolides showed good in vitro activity against $M$. synoviae strains all over the world previously $[5,12,14,16,26-30]$, but field strains 


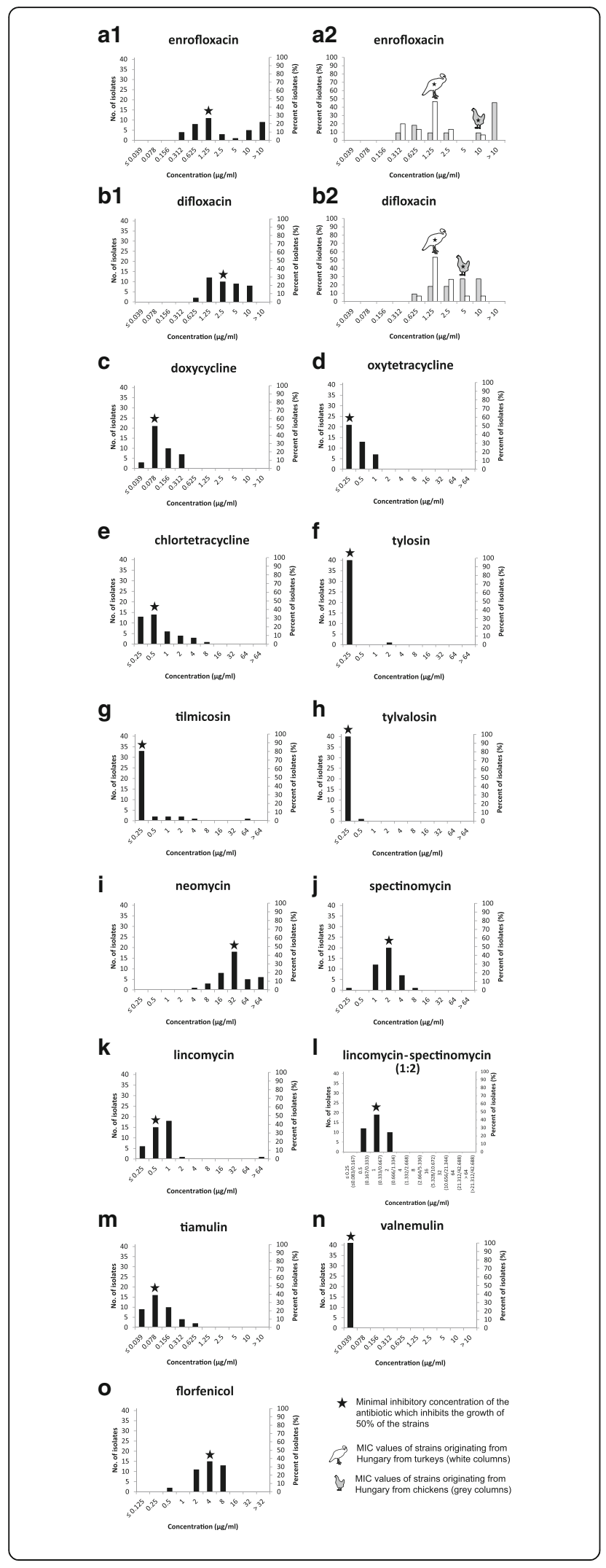

Fig. 1 MIC50 values are marked with asterisks. MIC values of 41 M. synoviae strains are demonstrated to enrofloxacin (a1), difloxacin (b1), doxycycline (c), oxytetracycline (d), chlortetracycline (e), tylosin $(\mathbf{f})$, tilmicosin $(\mathbf{g})$, tylvalosin $(\mathbf{h})$, neomycin (i), spectinomycin (j), lincomycin (k), the combination of lincomycin and spectinomycin (I), tiamulin ( $\mathbf{m})$, valnemulin $(\mathbf{n})$ and florfenicol $(\mathbf{o})$. The MIC values for enrofloxacin (a2) and difloxacin (b2) of isolates originating from Hungary from meat-type turkeys (white columns; $n=15$ ) and mostly breeder and layer chickens (grey columns; $\mathrm{n}=11$ ) are presented in individual diagrams also

showing intermediate susceptibility or resistance (MIC $>1 \mu \mathrm{g} / \mathrm{ml}$ according to Hannan [20]) have been isolated also, even from Europe [13]. In avian Mycoplasma strains resistance to tilmicosin developed more readily and quicker than to tylosin under laboratory conditions [31]. Several previous studies reported the slow increase of resistance to tylosin in M. synoviae and M. gallisepticum in vitro also $[7,32,33]$. In the current examination, the majority of the strains were inhibited by low concentrations of tylvalosin and tylosin, and $90 \%$ of the strains were susceptible to tilmicosin $(\leq 1 \mu \mathrm{g} / \mathrm{ml})$ [5], confirming the high in vitro efficiency of these macrolides against M. synoviae. Elevated MIC values were detected primarily in the case of tilmicosin (with four strains reaching MIC $>1 \mu \mathrm{g} / \mathrm{ml}$ ), which is concordant with previous observations in vitro [31], and assumes the more rapid development of resistance against this agent.

Lincosamides have similar protein synthesis inhibitory mechanism on the $50 \mathrm{~S}$ subunit of the bacterial ribosome as macrolides [34], and lincomycin was found to be efficacious against avian mycoplasmas before $[3,16]$. Cross-resistance was described between macrolides and lincosamides and it was associated with mutations in the 23S ribosomal RNA of $M$. synoviae [35]. In the current study, all isolates showed susceptibility $(\leq 2 \mu \mathrm{g} / \mathrm{ml})$ [20] to lincomycin except for one outlier strain (MYCAV 185; MIC $>64 \mu \mathrm{g} / \mathrm{ml}$ ), which showed elevated MIC values to macrolides as well.

Aminoglycosides and aminocyclitols are most commonly administered for the treatment of bacterial enteritis in poultry [36, 37], and by the oral application these compounds absorb poorly from the gastrointestinal tract [38]. Previous in vitro examinations on the efficacy of neomycin against $M$. synoviae revealed that high concentrations of the antibiotic were needed for the inhibition of the pathogen (MICs 32-128 $\mu \mathrm{g} / \mathrm{ml}$ ) [30]. On the other hand, spectinomycin proved to be effective against the French and Iranian M. synoviae strains in vitro with MIC values below the susceptibility breakpoint of $4 \mu \mathrm{g} /$ $\mathrm{ml}$ (according to CLSI [25]) [16, 28]. Potentially lower concentrations of spectinomycin were sufficient for the inhibition of the growth of M. synoviae when it was applied in combination with lincomycin [28], and this 
combination successfully controlled experimental $M$. synoviae infection in vivo before [9]. In the present study, the majority of the strains showed resistance to neomycin (MIC $>4 \mu \mathrm{g} / \mathrm{ml}$ according to CLSI [25]) but were inhibited by spectinomycin at concentrations below the assumed breakpoint (MIC $\leq 4 \mu \mathrm{g} / \mathrm{ml}$ [25]). The combination of lincomycin with spectinomycin improved the efficacy of both antibiotics against most $M$. synoviae strains (Tables 1 and 2 and Additional file 1); therefore the use of their combination is supposed to be preferable in the therapy.

Pleuromutilins showed high in vitro effect against avian mycoplasmas before $[7,13]$ and have been used in the treatment of mycoplasmosis in poultry [39]. Resistance against these substances in M. gallisepticum and M. synoviae develops gradually [7], as only one mutation is enough for the elevation of MIC values, but to achieve high level resistance the combination of multiple mutations is required [39]. The $M$. synoviae strains examined in this study showed high susceptibility to tiamulin and valnemulin, assuming their potential in the therapy.

Phenicols are broad-spectrum antibiotics and showed in vitro activity against certain mycoplasmas before $[23,30,38,40]$. In the present study, although two strains were inhibited by lower concentrations of florfenicol (MIC $0.5 \mu \mathrm{g} / \mathrm{ml}$ ), narrow range of MICs was observed among the rest of the strains (MICs between 2 and $8 \mu \mathrm{g} / \mathrm{ml}$ ), showing lower effectiveness of florfenicol against $M$. synoviae than reported in other studies or in M. gallisepticum [30, 40].

The observed differences between the initial and final MIC values of the mycoplasmastatic antibiotics chlortetracycline and lincomycin [34] lead to the recategorization of certain strains from susceptible to resistant during the interpretation of the results, while in other cases no difference was detected at all. Also, remarkable deviation of the MIC values for neomycin (which has concentration-dependent mycoplasmacidal effect [34]) was observed when initial and final readings were compared, although it did not alter significantly the interpretation of the data. Many factors may influence the growth of the bacteria in the in vitro tests; the discrepancies may indicate the inactivation of the used antibiotics during incubation, or the presence of a slower growing minor population which may have significance in the determination of official breakpoints in the future and in the estimation of the in vivo efficacy of the antibiotics $[20,24,26]$. The combined examination of the in vitro tests with pharmacokinetics/pharmacodynamics studies and in vivo experiments would probably enable the better understanding of the importance of the initial and final MIC values, and the differences in between.
Nevertheless, freshly prepared antibiotic solutions are administered during treatment, which minimize the possibility of antibiotic inactivation and initial MIC values are evaluated in the standardized methods for human pathogen mycoplasmas as well [22]; therefore the initial MIC values are advised to be taken into account in the interpretation of the results in mycoplasmas with veterinary relevance.

Strains originating from the same farm but from different years possessed similar MIC values (e.g. strains from farms 4, 13 and 14; Table 1). However, apart from oxytetracycline, doxycycline, tylvalosin, valnemulin and the combination of lincomycin and spectinomycin, strains with elevated MIC values were detected in the cases of all antibiotics tested. Even more, as an alarming example for irresponsible antibiotic usage, one strain (MYCAV 185) showed high MIC values to several antibiotics, especially to fluoroquinolones, macrolides and to lincomycin. It is noteworthy, that the combined application of lincomycin with spectinomycin remarkably reduced the inhibitory antibiotic concentration against this strain (from $\mathrm{MIC}_{\text {lincomycin }}>64 \mu \mathrm{g} / \mathrm{ml}$ to $\mathrm{MIC}_{\text {lincomy- }}$ cin:spectinomycin $2 \mu \mathrm{g} / \mathrm{ml}(0.666 / 1.334 \mu \mathrm{g} / \mathrm{ml}))$. All of these observations highlight the importance of testing the antibiotic susceptibility of $M$. synoviae before treatment. On the other hand, in clinical cases when rapid intervention is needed (e.g. mortality or high morbidity with severe clinical signs) and the treatment cannot wait for the results of the time-consuming and laborious in vitro tests, the presented data may serve as a guide in the choice of the appropriate antibiotic therapy in the Central and Eastern European region.

\section{Conclusions}

Antibiotic susceptibility testing of $M$. synoviae is laborious and time-consuming, and is not performed in routine diagnostics, thus empirical antibiotic treatment is usually applied by the clinicians. The MIC values of the $41 M$. synoviae strains provided in the present study revealed the in vitro effectiveness of tetracyclines, macrolides and pleuromutilins, and assume the potential usefulness of these agents in the therapy of mycoplasmosis in poultry in Central and Eastern Europe. However, elevated MIC values were observed in several cases during the examinations, which concerns antibiotics with importance in human medicine as well (e.g. fluoroquinolones). In order to preserve these critical antimicrobials for the therapy of humans, prudent antibiotic usage is recommended based on preliminary in vitro antibiotic susceptibility tests and on the careful evaluation of these data by considering the difficulties in the interpretation of the results and the factors influencing antibiotic effectiveness in vivo. 


\section{Additional file}

Additional file 1: Background data and initial and final MIC values of the isolated Mycoplasma synoviae strains. (XLS $61 \mathrm{~kb}$ )

\section{Abbreviation}

MIC: Minimal inhibitory concentrations

\section{Acknowledgements}

Not applicable

\section{Funding}

This work was funded by the National Research, Development and Innovation Office (K119594), by the Lendület (Momentum) program (LP2012-22) of the Hungarian Academy of Sciences and by the MycoPath 2 pan-European antimicrobial susceptibility monitoring programme. MG was supported by the Bolyai János Research Fellowship of the Hungarian Academy of Sciences. The funders had no role in study design, data collection, analysis and interpretation, decision to publish, or preparation of the manuscript.

\section{Availability of data and materials}

The dataset supporting the conclusions of this article is included in the article and additional file.

\section{Authors' contributions}

All authors read and approved the final version of this manuscript. ZK, DG, KMS, KN, DB collected the samples, analysed the data and wrote the manuscript. VH performed the examinations. MG designed the study, analysed the data and edited the manuscript.

\section{Ethics approval and consent to participate}

All samples were collected by the authors during routine diagnostic examinations or necropsies with the consent of the owners, thus ethical approval or specific permission was not required for the study. Consent to participate is not applicable.

\section{Consent for publication}

Not applicable

\section{Competing interests}

The authors declare that they have no competing interests.

\section{Publisher's Note}

Springer Nature remains neutral with regard to jurisdictional claims in published maps and institutional affiliations.

\section{Author details}

'Institute for Veterinary Medical Research, Centre for Agricultural Research, Hungarian Academy of Sciences, Hungária körút 21, Budapest 1143, Hungary. ${ }^{2}$ Biotechnical Faculty, University of Ljubljana, Groblje 3, SI-1230 Domžale, Slovenia.

Received: 3 July 2017 Accepted: 9 November 2017

Published online: 17 November 2017

\section{References}

1. Kleven SH. Control of avian mycoplasma infections in commercial poultry. Avian Dis. 2008:52:367-74.

2. Feberwee A, de Wit JJ, Landman WJ. Induction of eggshell apex abnormalities by Mycoplasma synoviae: field and experimental studies. Avian Pathol. 2009;38:77-85.

3. Stipkovits L, Kempf I. Mycoplasmoses in poultry. Rev Sci Tech. 1996;15: $1495-525$

4. Landman WJM. Is Mycoplasma synoviae outrunning Mycoplasma gallisepticum? A viewpoint from the Netherlands. Avian Pathol. 2014:43:2-8. doi: 10.1080/ 03079457.2014.881049.

5. Landman WJ, Mevius DJ, Veldman KT, Feberwee A. In vitro antibiotic susceptibility of Dutch Mycoplasma synoviae field isolates originating from joint lesions and the respiratory tract of commercial poultry. Avian Pathol. 2008:37:415-20.

6. McCormack WM. Susceptibility of mycoplasmas to antimicrobial agents: clinical implications. Clin Infect Dis. 1993;17(Suppl 1):200-1.

7. Gautier-Bouchardon AV, Reinhardt AK, Kobisch M, Kempf I. In vitro development of resistance to enrofloxacin, erythromycin, tylosin, tiamulin and oxytetracycline in Mycoplasma gallisepticum, Mycoplasma iowae and Mycoplasma synoviae. Vet Microbiol. 2002;88:47-58.

8. Kleven SH, Anderson DP. In vitro activity of various antibiotics against Mycoplasma synoviae. Avian Dis. 1971;15:551-7.

9. Hamdy AH, Kleven SH, McCune EL. Efficacy of Linco-Spectin water medication on Mycoplasma synoviae airsacculitis in broilers. Avian Dis. 1976;20:118-25.

10. Olson NO, Sahu SP. Efficacy of chlortetracycline against Mycoplasma synoviae isolated in two periods. Avian Dis. 1976;20:221-9.

11. Baughn CO, Alpaugh WC, Linkenheimer WH, Maplesden DC. Effect of tiamulin in chickens and turkeys infected experimentally with avian Mycoplasma. Avian Dis. 1978;22:620-6.

12. Bradbury JM, Yavari CA, Giles CJ. In Vitro evaluation of various antimicrobials against Mycoplasma gallisepticum and Mycoplasma synoviae by the microbroth method, and comparison with a commercially prepared test system. Avian Pathol. 1994:23:105-15.

13. Hannan PCT, Windsor GD, de Jong A, Schmeer N, Stegeman M. Comparative susceptibilities of various animal-pathogenic mycoplasmas to fluoroquinolones. Antimicrob Agents Chemother. 1997;41:2037-40.

14. Wang $C$, Ewing M, Aarabi SY. In vitro susceptibility of avian mycoplasmas to enrofloxacin, sarafloxacin, tylosin, and oxytetracycline. Avian Dis. 2001;45: 456-60.

15. McAuliffe L, Ellis RJ, Miles K, Ayling RD, Nicholas RA. Biofilm formation by mycoplasma species and its role in environmental persistence and survival. Microbiol. 2006:152:913-22.

16. Dufour-Gesbert F, Dheilly A, Marois C, Kempf I. Epidemiological study on Mycoplasma synoviae infection in layers. Vet Microbiol. 2006;114:148-54.

17. Lysnyansky I, Gerchman I, Mikula I, Gobbo F, Catania S, Levisohn S. Molecular characterization of acquired enrofloxacin resistance in Mycoplasma synoviae field isolates. Antimicrob Agents Chemother. 2013;57:3072-7.

18. Frey ML, Hanson RP, Anderson DP. A Medium for the isolation of avian mycoplasmas. Am J Vet Res. 1968;29:2163-71.

19. Lauerman LH, Chilina AR, Closser JA, Johansen D. Avian Mycoplasma identification using polymerase chain reaction amplicon and restriction fragment length polymorphism analysis. Avian Dis. 1995:39:804-11.

20. Hannan PCT. Guidelines and recommendations for antimicrobial minimum inhibitory concentration (MIC) testing against veterinary mycoplasma species. Vet Res. 2000;31:373-95.

21. Clinical and Laboratory Standards Institute (CLSI). Methods for antimicrobial susceptibility testing for human mycoplasmas; Approved guideline. CLSI document M43-A. Wayne PA: Clinical and Laboratory Standards Institute; 2011.

22. Waites KB, Duffy LB, Bébéar CM, Matlow A, Talkington DF, Kenny GE, Totten PA, Bade DJ, Zheng X, Davidson MK, Shortridge VD, Watts JL, Brown SD. Standardized methods and quality control limits for agar and broth microdilution susceptibility testing of Mycoplasma pneumoniae, Mycoplasma hominis, and Ureaplasma urealyticum. J Clin Microbiol. 2012;50:3542-7. doi: 10.1128/JCM.01439-12

23. Waites KB, Lysnyansky I, Bébéar CM. Emerging antimicrobial resistance in mycoplasmas of humans and animals. In: Browning G, Citti C, editors. Mollicutes: molecular biology and pathogenesis. Norfolk: Caister academic press; 2014. p. 289-322.

24. Gerchman I, Lysnyansky I, Perk S, Levisohn S. In vitro susceptibilities to fluoroquinolones in current and archived Mycoplasma gallisepticum and Mycoplasma synoviae isolates from meat-type turkeys. Vet Microbiol. 2008; 131:266-76. doi: 10.1016/j.vetmic.2008.04.006.

25. Clinical and Laboratory Standards Institute (CLSI). Performance standards for antimicrobial disk and dilution susceptibility tests for bacteria isolated from animals. Wayne, PA. Approved standard (fourth edition) and second informational supplement. CLSI document VET01-A4 and VET01-S2. In: CLSI 2013; 2013.

26. Cooper AC, Fuller JR, Fuller MK, Whittlestone P, Wise DR. In vitro activity of danofloxacin, tylosin and oxytetracycline against mycoplasmas of veterinary importance. Res Vet Sci. 1993:54:329-34.

27. Cerda RO, Giacoboni Gl, Xavier JA, Sansalone PL, Landoni MF. In vitro antibiotic susceptibility of field isolates of Mycoplasma synoviae in Argentina. Avian Dis. 2002;46:215-8. 
28. Behbahan NGG, Asasi K, Afsharifar AR, Pourbakhsh SA. Susceptibilities of Mycoplasma gallispeticum and Mycoplasma synoviae isolates to antimicrobial agents in vitro. Int J Poult Sci. 2008;7:1058-64.

29. Islam KMS, Klein U, Burch DGS. The activity and compatibility of the antibiotic tiamulin with other drugs in poultry medicine-a review. Poult Sci. 2009:88:2353-9.

30. Kibeida, OAl. A comparison of methods used to measure the in vitro antimicrobial susceptibilities of Mycoplasma species of animal origin. 2010; MSc dissertation, University of Pretoria, Pretoria. http://repository.up.ac.za/ handle/2263/26686?show=full Accessed 13 Nov 2017.

31. Wu CM, Wu H, Ning Y, Wang J, Du X, Shen J. Induction of macrolide resistance in Mycoplasma gallisepticum in vitro and its resistance-related mutations within domain V of $23 S$ rRNA. FEMS Microbiol Letters. 2005;247:199-205.

32. Zanella A, Martino PA, Pratelli A, Stonfer M. Development of antibiotic resistance in Mycoplasma gallisepticum in vitro. Avian Pathol. 1998;27:591-6.

33. Takahashi I, Yoshida T, Higashide Y, Sawada T. Vitro resistance acquisition in Mycoplasma gallisepticum against ofloxacin, tylosin and spectinomycin. Jpn J Antibiot. 2002;55:291-301.

34. Lysnyansky I, Ayling RD. Mycoplasma bovis: mechanisms of resistance and trends in antimicrobial susceptibility. Front Microbiol. 2016;7:595. doi: 10. 3389/fmicb.2016.00595.

35. Lysnyansky I, Gerchman I, Flaminio B, Catania S. Decreased susceptibility to macrolide-lincosamide in Mycoplasma synoviae is associated with mutations in 23 S ribosomal RNA. Microbial Drug Resist. 2015;21:581-9. doi: 10.1089/ mdr.2014.0290.

36. Marrett LE, Robb EJ, Frank RK. Efficacy of neomycin sulfate water medication on the control of mortality associated with colibacillosis in growing turkeys. Poult Sci. 2000;79:12-7.

37. Agunos A, Carson C, Léger D. Antimicrobial therapy of selected diseases in turkeys, laying hens, and minor poultry species in Canada. Can Vet J. 2013; 54:1041-52.

38. Goetting V, Lee KA, Tell LA. Pharmacokinetics of veterinary drugs in laying hens and residues in eggs: a review of the literature. J Vet Pharmacol Therap. 2011;34:521-56. doi: 10.1111/j.1365-2885.2011.01287.x.

39. Li BB, Shen JZ, Cao XY, Wang Y, Dai L, Huang SY, Wu CM. Mutations in $23 S$ rRNA gene associated with decreased susceptibility to tiamulin and valnemulin in Mycoplasma gallisepticum. FEMS Microbiol Letters. 2010;308:144-9.

40. Gharaibeh S, Al-Rashdan M. Change in antimicrobial susceptibility of Mycoplasma gallisepticum field isolates. Vet Microbiol. 2011;150:379-83.

41. Slavec B, Berčič RL, Cizelj I, Narat M, Zorman-Rojs O, Dovč P, Benčina D. Variation of $v / h A$ gene in Mycoplasma synoviae clones isolated from chickens. Avian Path. 2011;40:481-9.

42. Dušanić $\mathrm{D}$, Berčič RL, Cizelj I, Salmič S, Narat M, Benčina D. Mycoplasma synoviae invades non-phagocytic chicken cells in vitro. Vet Microbiol. 2009; 138:114-9.

43. Kempf I, Ollivier C, L'Hospitalier R, Guittet M, Bennejean G. Concentrations minimales inhibitrices de 13 antibiotiques vis-à-vis de 21 souches de mycoplasmes de volailles. Le Point Vétérinaire. 1989;20:935-40.

\section{Submit your next manuscript to BioMed Central and we will help you at every step:}

- We accept pre-submission inquiries

- Our selector tool helps you to find the most relevant journal

- We provide round the clock customer support

- Convenient online submission

- Thorough peer review

- Inclusion in PubMed and all major indexing services

- Maximum visibility for your research

Submit your manuscript at www.biomedcentral.com/submit 